\title{
Height, weight and food intake in man
}

\author{
By A. M. THOMSON AND W. Z. BILLEWICZ \\ Obstetric Medicine Research Unit (Medical Research Council), University of Aberdeen
}

\section{(Received I2 September 1960)}

Certain correlations between food intake and social status, height, weight and gain of weight during pregnancy were referred to in a previous series of papers (Thomson, $\left.195^{8}, 1959 a, b\right)$. In this paper, the same data, derived from a study of pregnant women, are used to investigate further the relationships of height and weight to diet.

The most interesting conclusion is that, contrary to popular belief and the implication of physiological teaching (e.g. F.A.O.: Second Committee on Calorie Requirements, 1957), heavy people do not as a rule eat much more than light people. A review of the literature suggests that this conclusion is valid also for men and for non-pregnant women.

\section{METHODS}

The dietary data used here were obtained from 489 primigravidae by means of a I-week weighing-inventory survey (Widdowson, I936). The technique used has been fully discussed and, so far as possible, validated (Thomson, 1958); any record considered by the dietitian concerned to be incomplete or unreliable was rejected. The diets were self-chosen, and no attempt was made by the obstetricians concerned to regulate the amount of weight which the subjects were gaining.

All subjects were weighed at the time of the dietary survey (about the $7^{\text {th }}$ month of pregnancy) and most were weighed at intervals throughout pregnancy. Weights at conception could not be assessed reliably, and for 412 out of the 489 subjects 'initial weight' has been taken as weight at the 2oth week of pregnancy, by which time all of them had been measured. All weighings were on calibrated lever balances reading to $2 \mathrm{oz}(57 \mathrm{~g})$ and subjects wore only underclothes during weighing. Shoes were removed during the measurement of standing height, which was recorded to the nearest 0.25 in. $(0.6 \mathrm{~cm})$. Since only $10.6 \%$ of the 489 subjects were aged 20 years or less, incomplete growth need not be considered when interpreting the height data.

Weight-for-height. The significance of a given body-weight $(W)$ varies with height $(H)$. To express weight-for-height, a mathematical index, such as $H / \sqrt[3]{W}$, is frequently used. Examination of the properties of several such indices showed that none of them discriminates uniformly over the whole range of heights; that is, the proportion of 'overweight' and 'underweight' individuals depends on height as well as on the value of the index. Some calculations based on the index $H / \sqrt[3]{2} W$, given on p. $25 \mathrm{I}$, show that it can yield misleading results. To overcome the difficulties, we have used a procedure devised during a previous study of weight gains during pregnancy (Thomson \& Billewicz, 1957). An unselected population of more than 4000 primigravidae was grouped according to height, $\mathrm{I}$ in. intervals being used. In each height group, the 
distribution of weights at the 2oth week of pregnancy was determined, and smoothed curves were drawn representing the quartiles in the successive distributions. In the present study these quartile values have been used to classify the $4 \mathrm{I} 2$ subjects for whom 20 th week weights are available; women in the lightest $25 \%$ at any given height are here described as 'underweight' and those in the heaviest $25 \%$ as 'overweight'. These terms are not, of course, to be interpreted as implying judgements on the degree of adiposity.

A theoretical objection to this procedure is that the distributions of body-weight might in fact tend to change with height. For example, tall women might take more care to avoid obesity than short women; if they did, the heaviest $25 \%$ of short women would be relatively more obese than the heaviest $25 \%$ of tall women. But, somewhat unexpectedly, the shapes of the weight distribution curves are similar throughout the whole range of heights, so that this objection does not appear to be valid so far as the present subjects are concerned. (The variance of weights increased with height, but the coefficients of variation were similar throughout the range of heights.)

Social class. Though data distinguished by social class are not presented in this paper, the term is used several times. It refers to a modification of the RegistrarGeneral's classification of occupations (General Register Office, 195 I). Briefly, women in social class A comprise those with husbands in professional, managerial, and other non-manual occupations. Husbands in class B did skilled manual work and those in class $\mathrm{C}$ semi-skilled or unskilled manual work. Further details can be found in a previous publication (Thomson, 1958).

\section{RESULTS}

As a background to the present findings a few statistics, already published, will be summarized. The multiple correlation coefficient of calorie intake on height and weight was 0.28 . For calorie intake and height the correlation coefficient was 0.24 ; for calorie intake and weight, 0.22; and for weight and height, 0.56 (Thomson, 1959a). The multiple correlation coefficient of weight gained from the 2oth to the 36 th week of pregnancy $(G)$ on weight at the 2oth week $(W)$ and calorie intake $(C)$ was $0^{\circ} 33$, the partial coefficients being $r_{G C . W}=0.28$ and $r_{G W . C}=0.13$. The correlation coefficient $r_{C G}$ was 0.30 , but the regression of weight gain on calorie intake was small, each increase of $100 \mathrm{kcal} /$ day being associated with a mean weight increase of only $0.02 \mathrm{lb} /$ week (0.009 kg/week) (Thomson, $1959 b$ ).

In this paper, the question asked is: What association is there between stature, weight and weight-for-height on the one hand, and the quantity and quality of the diet on the other?

\section{Height}

In Table I, the subjects are divided into three arbitrary groups according to height. The distribution of subjects by height is not representative of all Aberdeen primigravidae, because a disproportionately large number were selected from social class $\mathrm{C}$, in which average stature is low (Thomson, 1958). At the time of the dietary survey the mean weight of the tall women was about I I. $5 \mathrm{~kg}$ greater than that of the short women. 
and their mean daily calorie intake was just over $360 \mathrm{kcal}$ greater. After standardization, by regression, of the calorie intakes to mean body-weight for all heights, a difference of about $240 \mathrm{kcal} /$ day remained between the tall and the short groups. The lower part of Table I shows that the tall women were gaining weight more quickly than the short, but the rates of gain were not greatly different.

'Table I. Certain characteristics of $(A) 489$ pregnant women grouped according to their stature, and their mean daily calorie intakes as observed and after adjustment for differences of body-weight and $(B)$ of $4^{12}$ subjects for whom sufficient data on weight gains were available

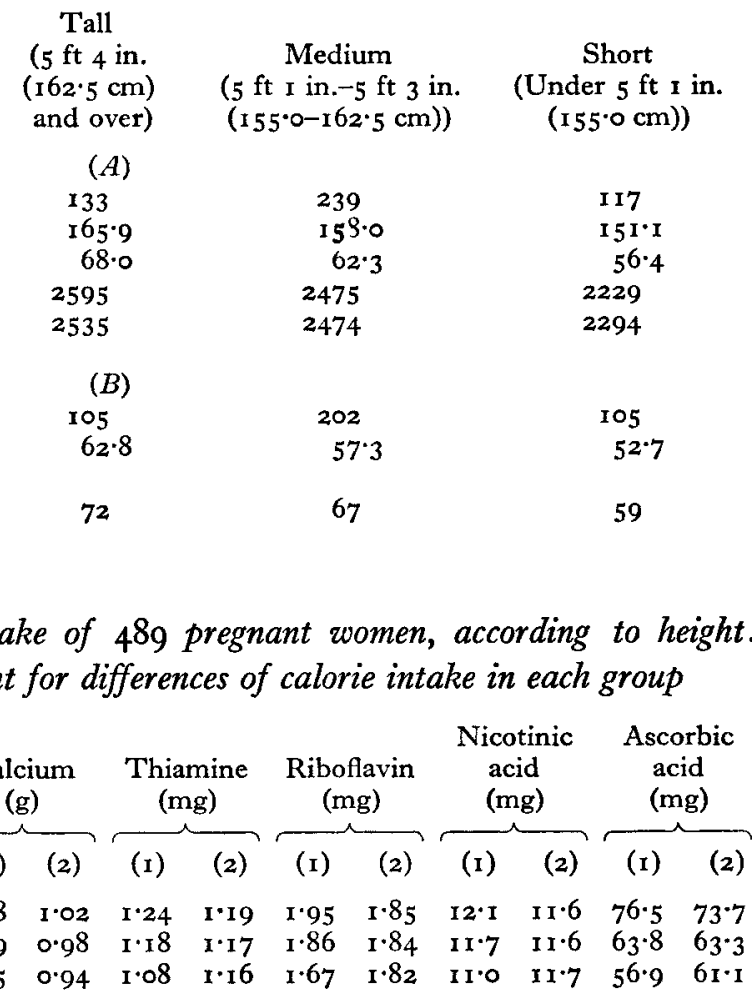

No. of subjects

Mean height $(\mathrm{cm})$

Mean weight $(\mathrm{kg})$

Observed calorie intake (kcal/day)

Calorie intake adjusted to mean bodyweight for all heights (kcal/day)

No. of subjects

Mean weight at 2oth week of pregnancy (kg)

Mean gain of weight 20 th-36th weeks of pregnancy $(\mathrm{g} /$ day $)$

Table 2. Mean daily nutrient intake of 489 pregnant women, according to height: (1) observed (2) after adjustment for differences of calorie intake in each group

\begin{tabular}{|c|c|c|c|c|c|c|c|c|c|c|c|c|c|c|}
\hline \multirow{2}{*}{$\begin{array}{l}\text { Height } \\
\text { (see } \\
\text { Table I) }\end{array}$} & \multicolumn{2}{|c|}{$\begin{array}{l}\text { Protein } \\
\text { (g) }\end{array}$} & \multicolumn{2}{|c|}{$\begin{array}{l}\text { Fat } \\
\text { (g) }\end{array}$} & \multicolumn{2}{|c|}{$\begin{array}{l}\text { Calcium } \\
\text { (g) }\end{array}$} & \multicolumn{2}{|c|}{$\begin{array}{c}\text { Thiamine } \\
\text { (mg) }\end{array}$} & \multicolumn{2}{|c|}{$\begin{array}{l}\text { Riboflavin } \\
\text { (mg) }\end{array}$} & \multicolumn{2}{|c|}{$\begin{array}{l}\text { Nicotinic } \\
\text { acid } \\
(\mathrm{mg})\end{array}$} & \multicolumn{2}{|c|}{$\begin{array}{c}\text { Ascorbic } \\
\text { acid } \\
\text { (mg) }\end{array}$} \\
\hline & (I) & (2) & (I) & (2) & (I) & (2) & (I) & (2) & (I) & (2) & (I) & (2) & (I) & (2) \\
\hline Tall & $80 \cdot 0$ & $76 \cdot 0$ & $109^{\circ} \mathrm{I}$ & $102 \cdot 7$ & $I \cdot 08$ & $1 \cdot 02$ & I. 24 & I.19 & I.95 & $I \cdot 85$ & $\mathrm{I} 2 \cdot \mathrm{I}$ & I I $\cdot 6$ & $76 \cdot 5$ & 73.7 \\
\hline Medium & $75 \cdot 1$ & $74 \cdot 4$ & $106 \cdot 1$ & 105.0 & 0.99 & 0.98 & $I \cdot 18$ & $1 \cdot 17$ & $I \cdot 86$ & $I \cdot 84$ & II 7 & $11 \cdot 6$ & 63.8 & 63.3 \\
\hline Short & $69 \cdot 2$ & $75 \cdot 2$ & $94 \cdot 6$ & 104.2 & 0.85 & 0.94 & $1 \cdot 08$ & $I \cdot 16$ & $1 \cdot 67$ & $I \cdot 82$ & II.O & II.7 & $56 \cdot 9$ & $6 I \cdot I$ \\
\hline
\end{tabular}

The differences between the adjusted means for calcium are almost significant $(0.05<P<0.10)$ and for vitamin $\mathrm{C}$ are highly significant $(P<0.01)$.

As shown previously ('Thomson, 1958 , 1959a), the intake of most nutrients tends to increase with calorie intake. Table 2 shows the observed mean intakes of certain nutrients in each height group, and the means after statistical adjustment, by regression, to allow for the differences of calorie intake shown in Table I. Values for vitamin A have not been included because the intakes of this vitamin were so variable that standardization could not yield meaningful results. Though the tall women took more of all the nutrients than the short women, most of the differences are accounted for by differences of calorie intake. The only exceptions were the differences in intakes of ascorbic acid and of calcium; this is due to the fact that, in relation to their calorie intake, the tall women ate more milk, cheese, vegetables and fruit than the short 
women, which raised their calcium and vitamin $\mathrm{C}$ intakes disproportionately to the rise in calorie intake.

\section{Weight}

In Table 3, the subjects are grouped according to their weights at the time of the dietary survey, the mean weights, heights and calorie intakes in each group being shown. It is obvious that the heavier women were taller and had higher calorie intakes. Calculations, not given here, have shown that the 'slope' of the increase of calorie intake with weight, although not completely eliminated, is reduced and not significant, when the calorie intakes are standardized by regression to the mean height of all the subjects. Trends similar to those in Table 3 were obtained when the data were reanalyzed on the basis of weights at the zoth week or during the first trimester of pregnancy (where available).

\section{Weight-for-height}

Table 4 describes the $4 \mathrm{I} 2$ women in the dietary survey for whom body-weight at the 20 th week of pregnancy was known. When they are grouped according to weightfor-height, it is found that the overweight women were on the average about $16 \mathrm{~kg}$

Table 3. Mean daily calorie intakes of 489 pregnant women grouped according to weight (about $7^{\text {th }}$ month of pregnancy)

\begin{tabular}{|c|c|c|c|c|}
\hline $\begin{array}{l}\text { Weight } \\
(\mathrm{kg})\end{array}$ & $\begin{array}{c}\text { No. of } \\
\text { subjects }\end{array}$ & $\begin{array}{c}\text { Mean weight } \\
(\mathrm{kg})\end{array}$ & $\begin{array}{l}\text { Mean height } \\
(\mathrm{cm})\end{array}$ & $\begin{array}{l}\text { Mean daily } \\
\text { calorie intake } \\
\text { (kcal) }\end{array}$ \\
\hline $40-$ & 5 & $43 \cdot 7$ & I $44 \cdot 5$ & 2134 \\
\hline $45^{-}$ & I I & $48 \cdot I$ & $151 \cdot 4$ & 2317 \\
\hline $5^{0-}$ & 61 & $52 \cdot 9$ & I 54.2 & 2357 \\
\hline $55^{-}$ & 126 & $57 \cdot 6$ & 156.7 & 2304 \\
\hline $60-$ & 110 & $62 \cdot 4$ & I 58.8 & 2442 \\
\hline $65-$ & 93 & $67 \cdot x$ & 160.8 & 2570 \\
\hline $70-$ & 47 & $71 \cdot 7$ & $162 \cdot 1$ & 2608 \\
\hline $75-$ & 18 & $76 \cdot 9$ & 164.6 & 2669 \\
\hline $80-$ & 18 & $84 . I$ & $167 \cdot 1$ & 2726 \\
\hline
\end{tabular}

Table 4. Average characteristics of 412 pregnant women in three weight-for-height categories (see p. 242), and mean nutritive values of their daily diets

\begin{tabular}{|c|c|c|c|}
\hline & Underweight & $\begin{array}{l}\text { Average } \\
\text { weight }\end{array}$ & Overweight \\
\hline No. of subjects & 94 & 204 & I 14 \\
\hline Mean weight at 20 th week of pregnancy $(\mathrm{kg})$ & $49 \cdot 9$ & $56 \cdot 5$ & $65 \cdot 6$ \\
\hline Mean height $(\mathrm{cm})$ & $158 \cdot 0$ & $158 \cdot 2$ & $158 \cdot 5$ \\
\hline Mean age (years) & 23.9 & $23 \cdot 5$ & $24 \cdot 0$ \\
\hline $\begin{array}{l}\text { Mean weight gain between } 20 \text { th and } 36 \text { th } \\
\text { weeks of pregnancy (g/day) }\end{array}$ & 65 & 64 & 71 \\
\hline Calories (kcal) & 2400 & 2460 & $245^{6}$ \\
\hline Protein $(\mathrm{g})$ & $72 \cdot 7$ & $75 \cdot 4$ & $75 \cdot 5$ \\
\hline Fat $(g)$ & $103 \cdot 0$ & $104 \cdot 3$ & $103 \cdot 6$ \\
\hline Calcium (g) & 0.96 & 0.97 & 0.98 \\
\hline Vitamin A (i.u.) & 8500 & 8150 & 7400 \\
\hline Thiamine (mg) & $I \cdot 13$ & $I \cdot 19$ & $I \cdot I 9$ \\
\hline Riboflavin (mg) & $x \cdot 83$ & 1.83 & $\mathrm{I} \cdot 83$ \\
\hline Nicotinic acid (mg) & $11 \cdot 6$ & I I 7 & I I 5 \\
\hline Ascorbic acid (mg) & $68 \cdot 4$ & $65 \cdot 5$ & $62 \cdot 4$ \\
\hline
\end{tabular}


heavier than the underweight women, but about the same in average height and age. It has also been ascertained that the social-class distributions in the three groups were similar. Despite the rather large differences in mean body-weight, the diets taken by the women in the three weight-for-height groups were strikingly similar in average nutritive value.

The absence of any appreciable increase of calorie intake with increasing weight-forheight has been confirmed by dividing the subjects according to social class and according to height, and repeating the analysis within groups.

\section{DISCUSSION}

It is necessary, first, to discuss the extent to which these findings were influenced by the fact that the subjects were pregnant women. Pregnancy must have caused an increase of average food intake. Published material and clinical experience indicate that appetite usually increases sharply during the first half of pregnancy and is maintained at the higher level or may decline slightly during the later stages (Thomson, 1958). If it is so, the diets measured during the 7 th month were probably similar in quantity to those taken in mid-pregnancy. Marked changes in dietary composition are not likely to have occurred.

Height will scarcely change during pregnancy but there is usually a considerable increase of body-weight. We estimate that, on the average, weight at the 20 th week was about $4 \mathrm{~kg}$ and at the 7 th month about $9 \mathrm{~kg}$ above that at conception. Evidence culled from records in Aberdeen and from the literature suggests that during the first 20 weeks of pregnancy tall women gain slightly more weight than short women. This difference is maintained after the 2oth week (Table I) but the cumulative effect means that, at most, the average tall woman gains from $\mathrm{I} \cdot 5$ to $2 \mathrm{~kg}$ more than the average short woman during the whole of pregnancy. Such a difference, which is partly explained by the fact that tall women usually have larger babies than short women, is much less than the difference between the mean absolute body-weights of the tall and short women: IO. $\mathrm{kg}$ at the 20 th week and $\mathrm{Ir} \cdot 6 \mathrm{~kg}$ at the time of the dietary survey. Similarly, although the overweight women gained weight during pregnancy at a slightly greater rate than the underweight women (Table 4), the effect was small compared with the difference in absolute body-weight $(16 \mathrm{~kg})$ at the 20 th week of pregnancy.

It appears, therefore, that only a small proportion of the differences in body-weight shown in the tables can be explained by differences of weight gained during pregnancy in each group. In order to simplify the following discussion, these small effects will be ignored. It is realized that to do so is not strictly justifiable, but provided the limitations are borne in mind this simplification does not appear to invalidate the conclusions to be drawn.

\section{Height, weight and diet}

The tall women took diets of higher average calorie value than the short women, and a difference of about $240 \mathrm{kcal} / \mathrm{day}$ remained after standardization for differences of body-weight (Table 1 ). The diets of the tall women contained more of all nutrients 
than those of the short women, and so far as calcium and vitamin $\mathrm{C}$ were concerned the excess could not be accounted for by the higher calorie intake (Table 2).

On the other hand, Table 3 shows that heavier (and taller) women took diets of higher calorie value than lighter (and shorter) women. Though the increase of calorie intake with body-weight is quite marked, it is not as large as would be expected from statements on calorie requirements. For example, the women of mean weight $67 \cdot x \mathrm{~kg}$ took $213 \mathrm{kcal} /$ day more than those of mean weight $52.9 \mathrm{~kg}$. According to FAO: Second Committee on Calorie Requirements (1957) such a difference in body-weight (which would, presumably, be accompanied by a commensurate increase in height) would mean a difference of $440 \mathrm{kcal} /$ day in requirement. For the reasons already indicated, such a discrepancy cannot readily be explained by the fact that our subjects were pregnant.

Statistical analysis has shown that equations derived from the present data will predict calorie intakes from heights and weights very imprecisely. That is, a large proportion of the individual variation in calorie intakes cannot be explained in terms of height and weight. Furthermore, height and weight separately have roughly similar importance in the prediction $\left(r_{C H . W}=0 . I_{4}\right.$ and $\left.r_{C W . H}=0 . \mathrm{II}\right)$. Much of the unexplained variance is no doubt attributable to differences of activity.

Interpretation is also complicated by the fact that women at the different ends of the height and weight range tend to be drawn from different social classes. For example, of the tall women shown in Table $\mathrm{I}, 34 \%$ were in social class A (wives of non-manual workers) whereas of the short women only $10 \%$ were in this class.

Previous work in Aberdeen dealing with the relationship between maternal social class, stature and reproductive performance (Illsley, 1954; Thomson, 1959c) suggests that the trends in Tables I, 2 and 3 may be at least partly explained as follows.

Where the environment and social milieu is satisfactory, children tend to grow well and in a healthy manner, and to become tall adults. A good upbringing implies a good diet which, though it may play only a minor part in determining the stature finally attained, probably encourages a trend to tallness; conversely, a poor diet impedes growth and may cause permanent stunting. Permanent stunting can certainly be caused by rickets. Most girls tend to carry into marriage the standards to which they became accustomed as children. A good upbringing also implies a good education, formal and informal, by virtue of which girls are more likely to attain 'white collar' occupations and in due course to marry men whose jobs have relatively high social status. In this manner, there arises an association between high social status, good diets and tallness. Table 2 shows that the tall women did in fact take 'better' diets than the short women; but it is not implied that the diets of the short women were deficient (Thomson, 1959a).

In Britain at least, wives in the upper social classes are probably accustomed to a more active mode of life than those in the lower classes. The tradition of fresh air and exercise is probably stronger. Furthermore, the wives of better-paid workers usually have larger houses, share them less often with relatives and other potential helpers and worry more about domestic appearances (Thompson, 1954). Very few of the subjects in this survey had paid domestic help. If energy expenditure tends to increase with 
rising social status, and hence with increasing stature, this would help to explain the differences of calorie intake shown in Table $\mathbf{x}$.

Since height and weight are quite closely correlated $(r=0.56)$ the increase of calorie intake with body-weight shown in Table 3 may also be partly due to increasing activity. But this suggestion is extremely tentative, since increasing weight may also be partly due to increasing obesity. As is shown below, obesity (increased weight without commensurate increase in height) is not accompanied by an increase of calorie intake and must therefore be associated with decreased activity.

\section{Weight-for-height and diet}

In Table 4 are shown three groups of similar mean height and social status, but of greatly dissimilar weight. Yet the difference of mean weight between the extreme groups, nearly $16 \mathrm{~kg}$, was associated with only a very small difference of mean calorie intake, which would just about account for the difference in the rate at which these two groups were gaining weight.

Since the groups were of similar height, it is certain that the overweight women carried more 'obesity tissue' than the underweight, though few of them were conspicuously fat. There is no doubt that basal metabolism is quite closely related to weight, and Kekwick (1960) has recently argued that obesity tissue has 'approximately the same oxygen uptake as the lean body mass and its contained fluids', at least under basal conditions. The metabolic efficiency of standardized work is not increased in obesity (McKee \& Bolinger, 1960). Therefore an obese person has to expend more energy both at rest and during a given activity than a non-obese person. Accordingly, if obesity is not associated with an increase of calorie intake, it must be associated with a reduction of activity.

It is not easy to decide what this would mean in ordinary life, but a rough indication may be obtained by using the data published by FAO: Second Committee on Calorie Requirements (1957). The overweight women weighed, on average, about $65 \mathrm{~kg}$ and the underweight about $50 \mathrm{~kg}$. Such a difference in weight is said to imply a difference of about $450 \mathrm{kcal}$ in calorie requirement. Calculations indicate that the overweight subjects could have been saving this amount of energy by lying in bed an hour or two longer, sitting down a great deal more, and avoiding nearly all the more strenuous forms of activity. Furthermore, they might have saved energy by working more slowly and by avoiding unnecessary movement. Again, the difference indicated by the FAO requirement scale, which is not intended to apply in obesity, may exaggerate the difference to be accounted for. In other words, the similarity of calorie intakes in Table 4 does not imply that implausibly great differences in mode of life must have been present between the groups.

\section{Evidence from the literature}

McCance, Widdowson \& Verdon-Roe (1938) found a small correlation between the calorie intakes of 130 pregnant women and their 'corrected' body-weights, which probably correspond fairly closely to our weights at 20 weeks. They tabulated their 
data in detail and we have been able to recalculate the material in order to make more detailed comparisons with our own findings. In brief, there is almost complete agreement.

Both these studies of pregnant women therefore indicate that calorie intakes do not increase as markedly with body-weight as would be expected from requirement schedules, and that there is scarcely any increase with weight-for-height. Such a conclusion cannot justifiably be extrapolated to cover men and non-pregnant women, but the literature affords a good deal of evidence that it is, in fact, generally valid.

Widdowson (1936) and Widdowson \& McCance (1936) studied sixty-three men and sixty-three non-pregnant women, respectively. They found no significant correlation between daily calorie intakes and body-weights expressed as a percentage above or below 'normal' for sex, age and height. Their only comment is that calorie intake does not appear to be the main factor in determining body-weight (Widdowson, 1936).

Davis \& Scoular (1957) and Walker (1959) found no correlation between the calorie intakes and body-weights in students of both sexes. R. Passmore (personal communication) has informed us that there was no correlation in the data relating to male and female students studied by Kitchin, Passmore, Pyke \& Warnock (1949). Grossman \& Sloane (1955) studied eighty-seven soldiers. They found that the correlation between body-weight and calorie intake, 'although significant, was low'; no figure is given.

There are, in addition, numerous reports on smaller groups of subjects. Without exception, those examined by us have failed to show any obvious tendency for calorie intake to increase with body-weight. Height data are practically never presented and no conclusion can be drawn on this basis.

In all these papers, the authors were not concerned primarily with the problem of diet in relation to physique; but this is the main theme in several papers on obesity. It should not be assumed that these papers invariably deal with a pathological state of affairs, since obesity is sometimes assumed to exist if weight-for-height exceeds 'normal' by comparatively small amounts.

Until fairly recently, it seems to have been assumed that obesity is associated with a high calorie intake. For example, Beaudoin \& Mayer (1953) were concerned with the reliability of dietary survey methods and concluded that the 'research dietary interview', which in contrast to other methods indicated that obese women had much higher calorie intakes than normal controls, yielded data 'apparently more consistent with physiologic considerations than the data obtained from food record methods'. Since then, Mayer and his associates have gone a considerable way towards establishing that, contrary to 'physiologic considerations' of the type previously in mind, obese individuals do not eat excessively (Johnson, Burke \& Mayer, 1956; Stefanik, Heald \& Mayer, 1959). Indeed, many of the obese adolescents studied by these authors had rellatively low calorie intakes. The same is true of obese adult women studied by Swanson, Roberts, Willis, Pesek \& Mairs (1955). The report of Johnson et al. (1956) reviews some of the literature and suggests that obesity is associated primarily with restriction of activity. Such restriction of activity in obese women has been demonstrated by Dorris \& Stunkard (1957), who quote Larsen as having previously shown the same thing in obese diabetic men and women. 
Thus, the published evidence for men and non-pregnant women points even more clearly than that for pregnant women to the absence of any marked association between calorie intake and body-weight. It seems reasonable to accept that any increase of calorie intake with body-weight is less, probably much less, than that implied by the FAO calorie allowances, and that increase of weight due to obesity is as a rule accompanied by a decrease of activity rather than by increased food consumption.

Nevertheless, the evidence in the literature does not permit accurate quantitative expression of the relationships between energy intake and expenditure on the one hand, and body size and composition on the other. Food intakes have been assessed by several methods, some perhaps of dubious reliability. Quantitative data on activity are almost completely absent. Heights and weights are seldom reported directly-the habit of reporting them only in percentages above or below 'normal' seems to be growing - and almost never in sufficient detail to permit exact comparisons and recalculations. Most studies of men and of non-pregnant women seem to have dealt with subjects from a fairly narrow social range. There is a need for studies of large and representative samples by methods of proved accuracy.

\section{Calorie requirements}

Since the allowances of FAO: Second Committee on Calorie Requirements (1957) appear not to agree in their trend with calorie-intake data, it is necessary to consider briefly their basis and limitations.

The FAO allowances were derived almost entirely from laboratory studies of energy expended under basal conditions, at rest, and during certain types of activity, usually standardized. Food intake seems to have been taken into account only when defining the reference man and woman. Thus, the reference woman, weighing $55 \mathrm{~kg}$, is assumed to require $2300 \mathrm{kcal}$ daily, a figure 'which corresponds approximately with observed intake as determined in food consumption studies'. With this point of reference and the 'necessary assumption... that the average activity of a population corresponds to that of the reference adults', data on energy expenditure are used to calculate that, for example, a $65 \mathrm{~kg}$ woman requires $2600 \mathrm{kcal}$ daily. This procedure implies that in a population where $65 \mathrm{~kg}$ is the appropriate reference body-weight, the average calorie intake will be about $2600 \mathrm{kcal}$ daily. But if any confirmatory data on intakes exist, we are not aware of them.

The evidence already reviewed suggests that the FAO allowance for increase of body-weight above the standard is too high. It is doubtful if present evidence permits an accurate assessment of the amount of reduction that is necessary, when it is borne in mind that the requirement scales are not applicable to obese populations. As noted above, accurate studies of representative healthy populations are needed.

In principle, there can be no doubt that calorie-requirement scales based primarily on experimental data should be checked by relating them to empirical experience and, if necessary, modified. There is already a precedent. The FAO report says that the physiological requirement specific to pregnancy is about $80000 \mathrm{kcal}$, but since physical activity is usually reduced during pregnancy the additional allowance in practice should be $40000 \mathrm{kcal}$. 


\section{Some basic problems}

Although overeating is undoubtedly a cause of obesity, it is not necessary to overeat conspicuously in order to become fat. One kg of 'obesity tissue' may be laid down at a cost of perhaps $6000 \mathrm{kcal}$ (Keys \& Brožek, I953). Body-weight can therefore increase by $\mathrm{I} \mathrm{kg}$ in about 4 months if calorie intake exceeds energy expenditure by as little as $50 \mathrm{kcal} /$ day, a quantity which is too small to measure easily or exactly by the somewhat crude methods available, especially in the field.

Under laboratory conditions, a given level of standardized activity involves a much larger and easily measured increase of energy expenditure in a heavy person as compared with a light person. This is also true of energy expended in walking (Mahadeva, Passmore \& Woolf, I953). According to Passmore \& Durnin (1955) in field studies 'larger errors are likely to arise from a failure to determine correctly the length of time spent in any activity rather than in any assessment of the metabolic cost of that activity'. If this view is correct, and if calorie intake does not increase rapidly with body-weight, it should not be difficult to show that a heavy, especially an obese, person habitually spends less time undertaking the more energetic forms of activity than a light person. Nevertheless, activity schedules may not be entirely reliable in this context. The heavy person may be more economical in expending energy, not so much in physiological terms as in terms of 'habit' (restlessness on the one hand, and deliberateness on the other). Much has been written on psychological factors in obesity, and it might repay to examine the problems from the point of view of 'habit' rather than of maladjustment.

More fundamentally, the basic problem is how body-weight is regulated despite wide daily variations of intake and output of energy. Apart from the regulatory mechanism, what determines the 'setting', in terms of which different persons tend to stabilize at different levels of body-weight? We all know some fortunate individuals who, without any attempt at conscious control, maintain a steady body-weight for year after year; and others for whom the effort to maintain 'normal' body-weight is a constant struggle.

This problem is of particular interest to those working in the field of reproduction. In women, childbearing and the menopause often result in a change, usually an increase, of body-weight. Is the trend to obesity with pregnancy simply due to the accumulation of reserve tissues which are not wholly lost, especially when breast feeding does not take place, or is there some alteration of endocrine control? The latter, presumably, is the reason for post-menopausal increase in weight. At present, little is known about the 'natural history' and social context of changes of body-weight. Epidemiological methods should be particularly useful in mapping out the field, and in suggesting the lines along which clinical and laboratory research should be most fruitful.

\section{Suitability of weight-for-height indices}

The method we have used to divide our subjects in terms of weight-for-height has the disadvantage that it depends on internal criteria specific to the population studied. From this point of view, an objective ponderal index is preferable. But all the indices we have examined cause distortion which leads to unlikely results. This situation will 
be illustrated in terms of a commonly used index, $H / \sqrt[8]{ } W$, height being in in. and weight in $\mathrm{lb}$. To cite one example from the literature, Stewart (1959) regarded women with an index of 12.0 or less as 'overweight for their height' and those with an index of more than $13^{\circ} \circ$ as 'underweight for their height'. On these criteria, a woman $5 \mathrm{ft}$ in height is regarded as overweight if she weighs more than $125 \mathrm{lb}$ and underweight if she weighs less than $98 \mathrm{lb}$, and a woman $5 \mathrm{ft}$ Io in. tall is 'overweight' at $198 \mathrm{lb}$ and 'underweight' if she weighs less than $156 \mathrm{lb}$. At such extremes, at least, the criteria do not seem entirely reasonable.

Table 5. Distribution of 412 primiparae according to height and the ponderal index $H / \sqrt[3]{W}(H$ in in., $W$ in $l b)$, and mean calorie intakes in the three groups differentiated by the index

$\begin{array}{lccccc}\text { Ponderal index } & \overbrace{\text { Short }} & \begin{array}{c}\text { Medium } \\ \text { Number of subjects }\end{array} & \text { All heights } & \text { Tall } \\ \text { Overweight (under } 12 \cdot 2) & 48 & 61 & 14 & 123 & \begin{array}{c}\text { Mean } \\ \text { calorie intake } \\ \text { (kcal/day) }\end{array} \\ \text { Average weight }(12 \cdot 2-12 \cdot 8) & 45 & 101 & 53 & 2394 \\ \text { Underweight }(12 \cdot 8 \text { or more) } & 12 & 40 & 38 & 90 & 2461 \\ & 12482\end{array}$

* See Table $\mathrm{r}$ for definitions of the height groups.

In Table 5, which applies the index to our own data, we have altered the criteria in order to obtain reasonably large numbers in the extreme groups, but this does not affect the principle. From the figures, it would appear that $46 \%$ of our short subjects and $13 \%$ of our tall subjects were overweight; conversely, i $1 \%$ of the short and $36 \%$ of the tall were underweight. Since the distributions of weight at all levels of height are closely similar, these differences cannot be regarded as plausible.

The fact that the ponderal index tends to segregate subjects in terms of height as well as of weight-for-height means that it may give misleading results if used to investigate the relationship of weight-for-height to a variable which is itself correlated with height. This is illustrated by the mean calorie values in Table 5 , from which it appears that calorie intakes decrease as weight-for-height, as defined by the index, increases. This trend is almost certainly an artifact attributable to the properties of the ponderal index. When the data of McCance et al. (1938) are subdivided in the same way, the conclusion is reached that their 'overweight' subjects took about $300 \mathrm{kcal} / \mathrm{day}$ less than their 'underweight' subjects.

\section{SUMMARY}

I. In a group of 489 pregnant women, calorie intakes tended to increase with stature. The increase of consumption could not be explained by the associated increase of body-weight.

2. Intakes of most nutrients increased with stature, in parallel with calorie intakes. The increases in calcium and vitamin $\mathrm{C}$ intakes were larger than could be accounted for by the associated rise in calorie intakes. 
3. Calorie intakes rose also with increasing body-weight but the rise was much smaller than expected from the FAO schedule of calorie requirements.

4. The taller and heavier women were, on average, superior in social status to the smaller and lighter women. It is suggested that this fact helps to explain the slightly superior diet of the tall women, and also that the taller and heavier women may have been slightly more active than the smaller and lighter women.

5. The calorie intakes of overweight and underweight women were closely similar. This implies that the relatively obese must have been less active than the non-obese.

6. These findings and conclusions are supported by other studies, reported in the literature, including those on men and non-pregnant women.

7. It is suggested that schedules of calorie requirements, which have been based mainly on laboratory studies of energy expenditure, need to be reviewed in the light of studies of food intake.

8. The misleading results that may be obtained when a simple ponderal index is used to express weight-for-height are discussed.

We wish to thank Dr Isabella Leitch, Professor R. C. Garry and Dr R. Passmore, as well as several colleagues in Aberdeen, for suggestions and criticism.

\section{REFERENCES}

Beaudoin, R. \& Mayer, J. (1953). F. Amer. diet. Ass. 29, 29.

Davis, A. N. \& Scoular, F. I. (1957). F. Nutr. 6x, 289.

Dorris, R. J. \& Stunkard, A. J. (1957). Amer. F. med. Sci. 233, 622.

F.A.O.: Second Committee on Calorie Requirements (1957). F.A.O. nutr. Stud. no. 15.

General Register Office (195 I). Classification of Occupations, I950. London, H.M. Stationery Office.

Grossman, M. I. \& Sloane, H. S. (1955). Amer. F. clin. Nutr. 3, 403.

Illsley, R. (1954). Brit. med. F. ii, 1520 .

Johnson, M. L., Burke, B. S. \& Mayer, J. (1956). Amer. F. clin. Nutr. 4, 37.

Kekwick, A. (1960). Brit. med. F. ii, 407.

Keys, A. \& Brožek, J. (1953). Physiol. Rev. 33, 245.

Kitchin, A. H., Passmore, R., Pyke, M. \& Warnock, G. M. (1949). Brit. F. soc. Med. 3, ro.

Mahadeva, K., Passmore, R. \& Woolf, B. (1953). F. Physiol. 121, 225.

McCance, R. A., Widdowson, E. M. \& Verdon-Roe, C. M. (1938). F. Hyg., Camb., 38, 596.

McKee, W. P. \& Bolinger, R. E. (1960). F. appl. Physiol. 15, I97.

Passmore, R. \& Durnin, J. V. G. A. (1955). Physiol. Rev. 35, $80 \mathrm{I}$.

Stefanik, P. A., Heald, F. P. Jr. \& Mayer, J. (1959). Amer. F. clin. Nutr. 7, 55.

Stewart, A. M. (1959). F. Obst. Gyn., Brit. Emp. 66, 739.

Swanson, P., Roberts, H., Willis, E., Pesek, I. \& Mairs, P. (1955). In Weight Control: A Collection of Papers Presented at the Weight Control Colloquium, p. 8o. Iowa State College Press.

Thompson, B. (1954). Med. Offr. 91, 235.

Thomson, A. M. (1958). Brit. F. Nutr. 12, 446.

Thomson, A. M. (1959a). Brit. $\mathcal{F}$. Nutr. 13, 190.

Thomson, A. M. (1959b). Brit. F. Nutr. r3, 509 .

Thomson, A. M. (1959c). Eugen. Rev. 5r, 3 .

Thomson, A. M. \& Billewicz, W. Z. (1957). Brit. med. F. i, 243.

Walker, S. E. (1959). S. Afr. F. med. Sci. 24, ro3.

Widdowson, E. M. (1936). F. Hyg., Camb., 36, 269.

Widdowson, E. M. \& McCance, R. A. (1936). F. Hyg., Camb., 36, 293. 